\title{
Üretiminde Çeşitli Gübre Karışımları Uygulanmış ve Farklı Zamanlarda Hasat Edilmiş Kekik (Thymus sipyleus BOISS. subsp. sipyleus BOISS. var. sipyleus L.) Bitkisinin Uçucu Bileșen Grupları
}

\begin{abstract}
Samim Yaşar ${ }^{1 *}$, Nevriye Sicim 1 (iD
Özet: Doğal ortamından köklenerek elde edilen Kekik (Thymus sipyleus BOISS. subsp. sipyleus BOISS. var. sipyleus L.) bitkisi Konya ili Beyşehir ilçesinde kültüre alınmıştır. Üretimde, Azot + Fosfor + Potasyum (K1), Mikro Elementler (Bor + Bakır + Demir + Mangan + Molibden + Çinko) (K3) ve Azot + Fosfor + Potasyum + Mikro Elementlerden (Bor + Bakır + Demir + Mangan + Molibden + Çinko) (K2 ve K4) oluşan gübre karışımları uygulanmıştır. Hasat Ağustos, Eylül ve Ekim 2019 olmak üzere üç ayrı dönemde gerçekleştirilmiştir. Elde edilen bulgularda, kekik bitkisinde monoterpen bileşiklerinin \%60.66 ile K4 gübreleme uygulaması örneğinin Ekim ayı hasadında, seskiterpen bileşiklerinin \%11.52 ile K0 kontrol örneğinin Eylül ayı hasadında ve alkol bileşiklerinin \%69.64 ile K1 gübreleme uygulaması örneğinin Eylül ayı hasadında en yüksek değerlere ulaştığı görülmüştür. Sonuç olarak, çeşitli gübre karışımlan kullanılarak farklı dönemlerde hasat edilen kekik bitkisi örneklerinde uçucu bileşen gruplarının miktarlarında farklılık oluşabileceği anlaşılmıştır. Bu durum, bitkiyi hammadde olarak kabul eden ilgili endüstriyel alanlar için hammadde içerik özellikleri bakımdan geniş bir yelpaze sunulabileceğini göstermiştir.
\end{abstract}

Anahtar kelime: Kekik, gübre karışuımı uygulamaları, hasat zamanı, çucu bileşen grupları, SPME, GC-MS.

\section{Volatile Component Groups of Thyme (Thymus sipyleus BOISS. subsp. sipyleus BOISS. var. sipyleus L.) Harvested at Different Times After Various Fertilizer Mixtures Applying During Production}

\begin{abstract}
Thyme (Thymus sipyleus BOISS. subsp. sipyleus BOISS. var. sipyleus L.) plant obtained by rooting from its natural environment was cultivated in Konya province Beyşehir district. In production, Nitrogen + Phosphorus + Potassium (K1), Micro Elements (Boron + Copper + Iron + Manganese + Molybdenum + Zinc) (K3) and Nitrogen + Pho sphorus + Potassium + Micro Elements (Boron + Copper + Iron + Manganese + Molybdenum + Zinc) (K2 and K4) formed fertilizer mixtures were applied. Thyme samples were harvested in three different periods as August, September and October 2019. The findings showed that the monoterpene compounds with $60.66 \%$ in the October harvest of thyme produced using K4 fertilizer mixture application, the sesquiterpene compounds with $11.52 \%$ in the September harvest of thyme (K0 control sample), and the alcohol compounds with $69.64 \%$ in the September harvest of thyme produced using K1 fertilizer mixture application reached the highest values. As a result, it was showed that the contents of volatile component groups could be differentiated in the thyme plant harvested in different periods after using various fertilizer mixtures during production. Thus, a wide range of raw materialcontent properties can be offered for the relevant industrial areas that accept thyme as a raw material.
\end{abstract}

Keywords: Thyme, fertilizer mixture applications, harvesting time, volatile component groups, SPME, GC-MS. 
${ }^{1}$ Address (adres): Isparta Uygulamalı Bilimler Üniversitesi, Orman Fakültesi, Orman Endüstri Mühendisliği Bölümü, 32260, Isparta.

*Corresponding author (sorumlu yazar): samimyasar@ isparta.edu.tr

Citation (atıf): Yaşar, S., Sicim, N. (2021) Üretiminde Çeşitli Gübre Karışımları Uygulanmış ve Farklı Zamanlarda Hasat Edilmiş Kekik (Thymus sipyleus BOISS. subsp. sipyleus BOISS. var. sipyleus L.) Bitkisinin Uçucu Bileşen Grupları. Bilge International Journal of Science and Technology Research, 5(2): 111-117.

\section{GİRIŞ}

Türkiye'de "Kekik" olarak adlandırılan Thymus türlerinden hastalıkların önlenmesi, iyileştirilmesi ve sağlığın sürdürülmesi için geleneksel ve modern tıpta sıkça faydalanılmaktadır. Bununla birlikte besin takviyeleri, bitkisel çay, baharat ve çeşni halinde besin maddesi olarak da tüketilmektedir (Başer, 2001). Thymus türleri gida endüstrisinde çeşitli besin maddelerinde lezzet verici olarak kullanılmalarının yanı sıra antimikrobiyal özelliklerinden dolayı gidalarda koruyucu madde olarak da değerlendirilmektedir. Kozmetik endüstrisinde sabun, krem ve losyonların üretilmesinde koku verici etkisinden yararlanılmaktadır. Thymus türlerine ait uçucu yağlar antioksidan özelliklerinden dolayı beslenmede destekleyici olarak yer bulmakta, ayrıca alternatif tıpta antifungal, antiseptik, antibakteriyel, antitussif, antispazmodik, ekspektoran ve analjezik olarak değerlendirilmektedir (Cosentino vd., 1999; Hedhili vd., 2002; Rasooli ve Mirmostafa, 2002; Kabouche vd., 2005, Ra sooli vd., 2006; Selvi vd., 2012; Sargin vd., 2015).

La miaceae (Labia tae) fa milya sının en ta nınmış cinslerinden olan Thymus L., Türkiye'de 39 tür ve 60 takson ile temsil edilmekle birlikte endemiklik oranının \%45 olduğu bilinmektedir (Başer, 2002). Thymus sipyleus BOISS. subsp. sipyleus BOISS. var. sipyleus L., 400-2700 m yükseltilerdeki dağ bozkırları ve kayalık yamaçları yetişme a lanı olarak seçen çok yıllık bir bitkidir. Yarı çalı yetişme formuna sahiptir ve 5-8 adet çiçeklenme yapmaktadır. Yayılış alanını Türkiye ve Ege adalanı oluşturmaktadır (Tübives, 2021).

Türkiye'de, 2019 yılında 157074 dekarlık alanda 17965 ton kekik üretimi yapılmış ve 16756 ton kekik ihracatı gerçekleştirmiştir (TÜİK, 2020a ve 2020b). Bununla birlikte geçmişten bugüne kekik yetişme alanlarının azaldığına dikkat çekilmektedir. Aşırı faydalanma sebebiyle kekik üretim alanlarındaki tahribatın artması ve bazı endemik türlerin yok olmaya yüz tutması, kekiğin kültüre alınarak yetiştirilmesine yönelik çalışmaları gündeme getirmiştir (Baydar, 2001; Baydar, 2002; Karlı vd., 2020). Önceleri ihracatı gerçekleştirilen kekiğin \%95'i doğal ortamından sağlanırken (Sarı ve Oğuz, 2002; Şafak ve Okan, 2004), son y1llarda ihraç edilen kekiğin \%50'sinin tarımsal alanlardan temin edildiği belirtilmiştir (Özgüven vd., 2005).

Gübreleme, bitkisel üretimde verim ve kalitenin artırılmasına yönelik uygulanan çeşitli yöntemlerden birisini oluşturmaktadır. Gübreleme yolu ile bitki besin elementlerinin takviyesi yapılmaktadır. Bitki besin maddeleri, bitkinin büyümesi ve gelişmesi için gerekli olan ve başka kimyasal elementler ile ikame edilemeyen maddeleridir (Gezgin ve Hamurcu, 2006). Besin elementleri, bitki gelişiminde önemli rol oynamaktadırlar ve bir veya birkaçının eksikliği verim ve kalitede olumsuz etkiler yaratmaktadir (Fageria vd., 2002; Rice, 2007; Saraçoğlu vd., 2014). Bitki gelişiminde mutlaka gerek duyulan 17 element söz konusudur. Bunlar makro ve mik ro elementler olarak iki grupta değerlendirilmektedirler. Makro elementler karbon, hidrojen, oksijen, azot, fosfor, potasyum, kalsiyum, magnezyum ve kükürtten, mikro elementler ise demir, mangan, çinko, bakır, bor, klor, nikel ve molibdenden oluşmaktadır (Çepel, 1996; Jones ve Jacobsen, 2001; Epstein ve Bloom, 2005). Söz konusu makro ve mikro elementler bitkiler tarafindan toprak, ha va ve sudan tedarik edilmektedirler. Mineral olmayan besin elementleri olarak düşünülen karbon, hidrojen ve oksijen bitkiler tarafından çoğunlukla hava ve sudan a linmaktadırlar (Jones ve Jacobsen, 2001; Fageria, 2009; Kacar ve Katkat, 2010). Diğer zorunlu 14 element ise bitkilerce doğrudan topraktan alınmaktadırla r(Wild, 1993; Kantarc1, 2000; Gardiner ve Miller, 2008).

Birçok bitkisel üründe birim alandan en yüksek verim elde edilmesi amaçlanırken, tıbbi ve aromatik bitkilerde yüksek verimin yanı sıra birim alandan elde edilen etken madde verimi ve kalitesi de önem arz etmektedir. Çünkü bu bitkilerde esas olarak kullanılan kısım öncelikle uçucu ya ğ olmak üzere o bitkinin bileşimini oluşturan maddelerdir (Bayar ve Çınar, 2020). Thymus türlerinin uçucu yağ içeriklerinde en önemli bileșenlerin timol, karvakrol, linalool, p-simen, geraniol ve borneol olduğunu ortaya konmuş ve bitki dünyasında monoterpenoid alkollerin en önemli kaynağının Thymus türleri olduğu belirtilmiştir (Stahl-Biskup, 2002).

$\mathrm{Bu}$ çalışmada, doğal yetişme a lanından köklenerek alınan kekik (Thymus sipyleus BOISS. subsp. sipyleus BOISS. var. sipyleus L.) bitkisi kültüre alınmış, devamında makro ve mikro besin elementlerinden oluşan çeşitli gübre karışımları uygulanmış ve birer ay arayla üç ayrı dönemde ürün hasadı yapılmıştır. Kekik bitkisine ait örneklerdeki uçucu bileşenlerin izolasyonunda SPME (katı faz mikro ekstraksiyon) yöntemi uygulanarak analizler GC-MS ile gerçekleştirilmiştir. Gübreleme uygulamaları ve hasat zamanlarının kekik bitkisine ait uçucu bileşenlerin oluşturduğu gruplar üzerine etkileri değerlendirilmiştir.

\section{MATERYAL VE YÖNTEM}

Konya ili Beyşehir ilçesi Muslu Yayla mevkii $1750 \mathrm{~m}$ yükseltiden 23 Mayıs 2019 tarihinde köklenerek temin edilen kekik bitkisi, Konya ili Beyşehir ilçesi İslibucak mevkii 1345 m yükseltide kültüre alınmıştır. Köklendirme 
süreci 24 Haziran 2019 tarihine kadar devam etmiş ve bu dönemde sadece sulama işlemi gerçekleştirilmiştir. Köklendirme aşaması tamamlanan kekik bitkileri, farklı gübre uygulamaları ile yetiştirilmiştir. Gübreleme, 5 adet bitkiden oluşan her bir gruba Azot + Fosfor + Potasyum $2+$ $2+2$ g/bitki (K1), Azot + Fosfor + Potasyum + Mikro Elementler (Bor + Bakır + Demir + Mangan + Molibden + Çinko) $2+2+2+0.25$ g/bitki (K2 ve K4), Mikro Elementler (Bor + Bakır + Demir + Mangan + Molibden + Çinko) $0.25 \mathrm{~g} /$ bitki (K3) şeklinde yapılmıştır. K1, K2, K3 ve K4 uygulamalarında, gübreleme bitki başına 2 L sıv1 halinde 5 günlük periyodlarda saat 17:00 ile 20:00 a rasında gerçekleştirilmiştir. Gübreleme şekli K1, K2 ve K3 uygulamalarında topraktan gübreli su verilerek, K4 uygulamasinda ise bir sulamada topraktan gübreli su, bir sulamada tatlı su verilerek düzenlenmiştir. Doğal yetişme ortamında takibi yapılarak elde edilen örnek kontrol (K0) olarak kullanılmıştır. Kekik bitkisine ait örnekler 02 Ağustos 2019,02 Eylül 2019 ve 02 Ekim 2019 olmak üzere üç ayrı dönemde hasat edilmiştir. Örneklerin toprak üstü kısımlarının kurutulması oda sıcaklığında karanlık bir ortamda gerçekleştirilmiştir (Yaşar ve Sicim, 2021).

Kurutulan örneklere SPME ve GC-MS analizleri Yaşar ve Sicim (2021)'e göre yapılmıştır. Elde edilen bulguların istatiksel değerlendirilmesi için Basit varyans analizi (Anova Testi) ve Duncan testi, MiniTab 16 program 1 kullanılarak gerçekleştirilmiştir.

\section{BULGULAR VE TARTIŞMA}

Kültüre alınmış kekik bitkisinin çeşitli gübre karışımı uygulamaları ile yetiştirilmiş örneklerindeki bileşen gruplarına ait miktarlar Çizelge 1'de verilmiştir. Varyans analizi sonucunda bileşen gruplarının $p<0.001$ düzeyinde farklılaştığı görülmüş ve Duncan testine göre ortaya çıkan homojen gruplar verilmiştir.

Çizelge 1. Gübre karışımı uygula malarının kekik bitkisi uçucu bileşen gruplarına etkileri

\begin{tabular}{|l|r|r|r|r|r|}
\hline Bileșen grupları & KO (\%) & K1 (\%) & K2 (\%) & K3 (\%) & K4 (\%) \\
\hline Ăgustos hasadı & \multicolumn{5}{|c|}{} \\
\hline Monoterpen & $48.63 \mathrm{a}^{1}$ & $38.09 \mathrm{~b}$ & $45.75 \mathrm{c}$ & $36.03 \mathrm{~d}$ & $40.24 \mathrm{e}$ \\
\hline Seskiterpen & $6.95 \mathrm{a}$ & $6.70 \mathrm{a}$ & $4.30 \mathrm{~b}$ & $6.91 \mathrm{a}$ & $10.36 \mathrm{c}$ \\
\hline Alkol & $39.44 \mathrm{a}$ & $50.91 \mathrm{~b}$ & $45.24 \mathrm{c}$ & $51.92 \mathrm{~d}$ & $47.15 \mathrm{e}$ \\
\hline Eylül hasadı & \multicolumn{5}{|c|}{} \\
\hline Monoterpen & $39.94 \mathrm{a}$ & $19.66 \mathrm{~b}$ & $30.4 \mathrm{c}$ & $30.62 \mathrm{c}$ & $38.83 \mathrm{~d}$ \\
\hline Seskiterpen & $11.52 \mathrm{a}$ & $7.95 \mathrm{~b}$ & $6.61 \mathrm{c}$ & $4.94 \mathrm{~d}$ & $8.25 \mathrm{~b}$ \\
\hline Alkol & $40.15 \mathrm{a}$ & $69.64 \mathrm{~b}$ & $55.42 \mathrm{c}$ & $60.56 \mathrm{~d}$ & $51.98 \mathrm{e}$ \\
\hline Ekim hasadı & \multicolumn{5}{|c|}{} \\
\hline Monoterpen & $52.06 \mathrm{a}$ & $39.37 \mathrm{~b}$ & $43.19 \mathrm{c}$ & $50.41 \mathrm{~d}$ & $60.66 \mathrm{e}$ \\
\hline Seskiterpen & $2.89 \mathrm{a}$ & $3.97 \mathrm{~b}$ & $3.70 \mathrm{c}$ & $2.81 \mathrm{a}$ & $1.98 \mathrm{~d}$ \\
\hline Alkol & $37.21 \mathrm{a}$ & $51.58 \mathrm{~b}$ & $46.62 \mathrm{c}$ & $41.86 \mathrm{~d}$ & $31.13 \mathrm{e}$ \\
\hline
\end{tabular}

1: Duncan testi ile belirlenen homojen gruplar monoterpen, seskiterpen ve alkol bileşikleri için her satırda farklı harflerle ifade edilmiştir, $p<0.001$

Monoterpen bileşikleri miktarında, ağustos ve eylül hasatlarında K0 örneğine göre tüm gübreleme uygulamalarına ait örneklerde düşüş görülmüştür. Ekim hasadında ise $\mathrm{K} 0$ örneğine göre $\mathrm{K} 1, \mathrm{~K} 2$ ve $\mathrm{K} 3$ örneklerinde monoterpen bileşikleri miktarında a zalış, K4 örneğinde artış tespit edilmiştir. Seskiterpen bileşikleri miktarında, a ğustos hasadında K0 örneğine göre K4 örneğinde belirgin bir artış ortaya çıkmış, eylül hasadında ise $\mathrm{K} 0$ örneğine göre $\mathrm{K} 1$, $\mathrm{K} 2$, K3 ve K4 örneklerinde belirgin bir düşüş saptanmıştır. Ekim hasadında, $\mathrm{K} 0$ örneğine göre gübreleme uygulamalan sonucu elde edilen örneklerde seskiterpen bileşikleri miktarında sadece küçük değişiklikler gözlenmiştir. Alkol bileşiklerinin miktarında, ağustos ve eylül hasatlarında $\mathrm{K} 0$ örneğine göre $\mathrm{K} 1, \mathrm{~K} 2$, K3 ve K4 örneklerinde belirgin bir artışın oluştuğu belirlenmiştir. Ekim hasadında ise $\mathrm{K} 0$ örneğine göre alkol bileşikleri miktarının K1, K2 ve K3 örneklerinde yükseldiği, K4 örneğinde azaldığı görülmüsştür (Çizelge 1).

Kültüre alınmış kekik bitkisinin farklı hasat zamanlarında toplanan örneklerindeki bileşen gruplarına ait miktarlar Çizelge 2'de verilmiştir. Yapılan varyans analizine göre farklı hasat zamanlarında bileşen grupları arasında ista tistiki olarak önemli $(p<0.001)$ farklar tespit edilmiştir. 
Çizelge 2. Hasat zamanının kekik bitkisi uçucu bileşen grupla rına etkileri

\begin{tabular}{|c|c|c|c|}
\hline Bileşen grupları & Ăgustos hasadı (\%) & Eylül hasadı (\%) & Ekim hasadı (\%) \\
\hline \multicolumn{4}{|l|}{ KO } \\
\hline Monoterpen & $48.63 \mathrm{a}^{1}$ & $39.94 \mathrm{~b}$ & $52.06 \mathrm{c}$ \\
\hline Seskiterpen & $6.95 \mathrm{a}$ & $11.52 \mathrm{~b}$ & $2.89 \mathrm{c}$ \\
\hline Alkol & $39.44 \mathrm{a}$ & $40.15 \mathrm{~b}$ & $37.21 \mathrm{c}$ \\
\hline \multicolumn{4}{|l|}{ K1 } \\
\hline Monoterpen & $38.09 \mathrm{a}$ & $19.66 \mathrm{~b}$ & $39.37 \mathrm{c}$ \\
\hline Seskiterpen & $6.70 \mathrm{a}$ & $7.95 \mathrm{~b}$ & $3.97 \mathrm{c}$ \\
\hline Alkol & $50.91 \mathrm{a}$ & $69.64 \mathrm{~b}$ & $51.58 \mathrm{c}$ \\
\hline \multicolumn{4}{|l|}{ K2 } \\
\hline Monoterpen & $45.75 \mathrm{a}$ & $30.4 \mathrm{~b}$ & $43.19 \mathrm{c}$ \\
\hline Seskiterpen & $4.30 \mathrm{a}$ & $6.61 \mathrm{~b}$ & $3.70 \mathrm{c}$ \\
\hline Alkol & $45.24 \mathrm{a}$ & $55.42 \mathrm{~b}$ & $46.62 \mathrm{c}$ \\
\hline \multicolumn{4}{|l|}{ K3 } \\
\hline Monoterpen & $36.03 \mathrm{a}$ & $30.62 \mathrm{~b}$ & $50.41 \mathrm{c}$ \\
\hline Seskiterpen & $6.91 \mathrm{a}$ & $4.94 \mathrm{~b}$ & $2.81 \mathrm{c}$ \\
\hline Alkol & $51.92 \mathrm{a}$ & $60.56 \mathrm{~b}$ & $41.86 \mathrm{c}$ \\
\hline \multicolumn{4}{|l|}{ K4 } \\
\hline Monoterpen & $40.24 \mathrm{a}$ & $38.83 \mathrm{~b}$ & $60.66 \mathrm{c}$ \\
\hline Seskiterpen & $10.36 \mathrm{a}$ & $8.25 \mathrm{~b}$ & $1.98 \mathrm{c}$ \\
\hline Alkol & $47.15 \mathrm{a}$ & $51.98 \mathrm{~b}$ & $31.13 \mathrm{c}$ \\
\hline
\end{tabular}

1: Duncan testi ile belirlenen homojen gruplar monoterpen, seskiterpen ve alkol bileşikleri için her satırda farklı harflerle ifade edilmiştir, $p<0.001$

Monoterpen bileşikleri miktarı, K0, K1, K3 ve K4 örneklerinin eylül hasadında ağustos hasadına göre düşüş sergilerken, ekim hasadında artış göstermiştir. Ancak, K2 örneğinin ekim hasadında monoterpen bileșikleri miktarının a ğustos hasadına göre azaldığı gözlenmiştir. Seskiterpen bileşikleri miktarında, K0, K1 ve K2 örneklerinin ağustos hasadına göre eylül hasadında artış, buna karşın ekim hasadında düşüş belirlenmiştir. K3 ve K4 örneklerinin ağustos hasadından itibaren diğer hasat dönemlerinde seskiterpen bileşikleri miktarında sürekli bir düşüş saptanmıştır. Alkol bileşikleri miktarında $\mathrm{K} 1$ ve $\mathrm{K} 2$ örneklerinin eylül ve ekim hasatlarında ağustos hasadına göre daha yüksek değerler elde edilmiştir. Diğer örneklerde alkol bileşiklerinin miktarı ağustos hasadına göre eylül hasadında yükselmiş, ekim hasadında azalmıştır (Çizelge 2).

Monoterpen bileşikleri \%60.66 ile K4 gübreleme uygulaması örneğinin ekim hasadı, seskiterpen bileşikleri \%11.52 ile K0 kontrol örneğinin eylül hasadı ve alkol bileșikleri \%69.64 ile K1 gübreleme uygulamas1 örneğinin eylül hasadında en yüksek değerde elde edilmiştir (Şekil 1).

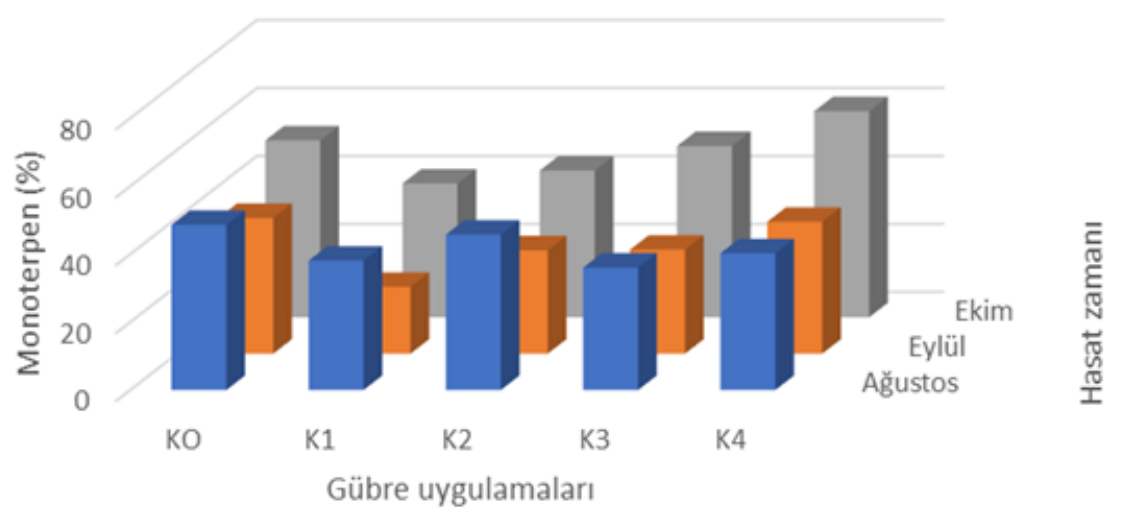




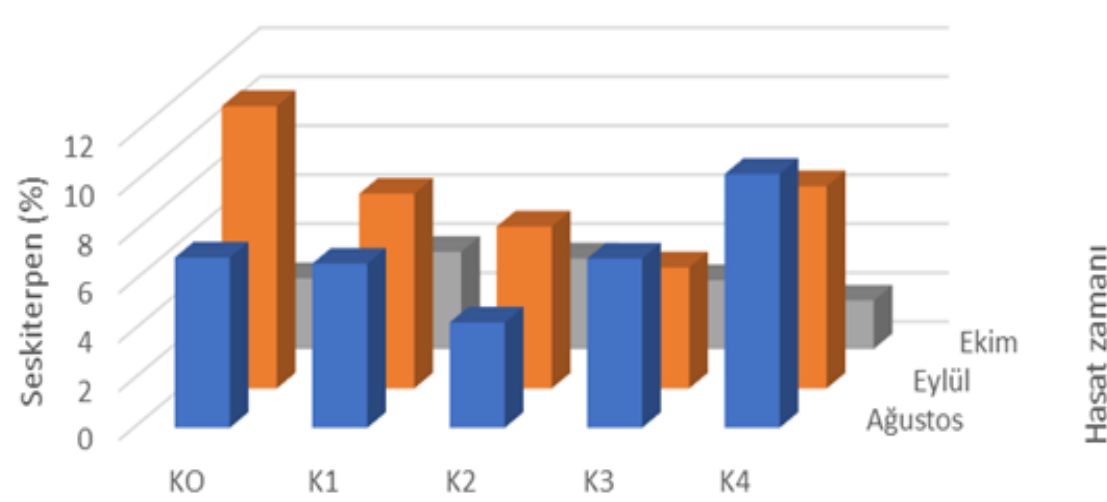

Gübre uygulamaları

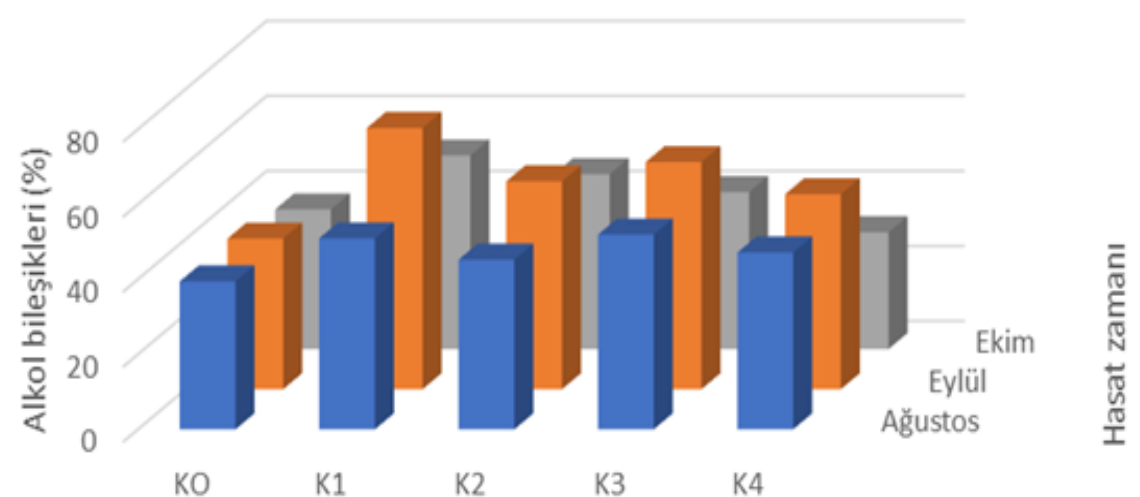

Gübre uygulamaları

Şekil 1. Kekik bitkisi uçucu bileşen grupları

Kekik bitkisi üretiminde kullanılan gübreleme uygulamalarının, elde edilen örneklerde monoterpen ve alkol bileşiklerinin oranında çoğunlukla artış sağladığı, seskiterpen bileşiklerinin oranında düşüşe neden olduğu söylenebilir. Yaşar ve Sicim (2021), kekik bitkisi K4 gübre karışımı uygulamasının ekim hasadında $p$-simen oranını $\% 43.76$ ve $\gamma$-terpinen oranını $\% 8.85, \mathrm{~K} 1$ gübre karışımı uygulamasının eylül hasadında karvakrol oranını \%67.01 olarak belirtmişlerdir. $\mathrm{Bu}$ durum, söz konusu bileşiklerin kekik bitkisinin K4 gübre karışımı uygulamasının ekim hasadından elde edilen örneklerde monoterpen ve K1 gübre karışımı uygulamasının eylül hasadından elde edilen örneklerde alkol bileşiklerinin oranının yüksek değerlerde elde edilmesine neden olduklarını göstermektedir. Aynı çalışmada, K0 kontrol örneğinin eylül hasadında monoterpen bileşikleri $p$-simen ile $\gamma$-terpinen ve alkol bileşikleri timol ile karvakrol oranlarının göreceli olarak düşük oluşu seskiterpen bileşiklerinin oranının yüksek olma sını açıkla maktadır.

\section{SONUÇ VE ÖNERILER}

Doğal ortamından elde edilen kekik (Thymus sipyleus BOISS. subsp. sipyleus BOISS. var. sipyleus L.) bitkisi Konya ili Beyşehir ilçesinde kültüre alınmıştır. Bitkinin üretiminde Azot + Fosfor + Potasyum (K1), Mikro Elementler (Bor + Bakır + Demir + Mangan + Molibden + Çinko) (K3) ve Azot + Fosfor + Potasyum + Mikro Elementler $($ Bor + Bakır + Demir + Mangan + Molibden +
Çinko) (K2 ve K4) gübre karışımları kullanılmış, ağustos, eylül ve ekim 2019 aylarında üç ayrı dönemde hasat gerçekleştirilmiştir. Monoterpen bileşiklerinin \%60.66 ile K4 gübreleme uygulamas1 örneğinin ekim hasad1, seskiterpen bileşiklerinin \%11.52 ile K0 kontrol örneğinin eylül hasadı ve alkol bileşiklerinin \%69.64 ile K1 gübreleme uygulaması örneğinin eylül hasadında en yüksek değerde olduğu görülmüştür. Çalışma bulguları, çeşitli gübre karışımları kullanılarak farklı dönemlerde hasat edilen kekik bitkisi örneklerinin uçucu bileşen gruplarının miktarlarında farklılaşma gerçekleştirilebileceğini göstermiştir. $\mathrm{Bu}$ durum, bitkiyi hammadde olarak kabul eden ilgili endüstriyel alanlar için hammadde içerik özellikleri bakımdan geniş bir yelpaze sunulabileceğini ortaya koymuştur.

\section{Teşekkür}

Bu çalışma, Isparta Uygulamalı Bilimler Üniversitesi BAP Koordinasyon Birimi tarafından sağlanan 2019-YL1-0039 nolu proje desteği ile gerçekleştirilmiştir. Sağlamış oldukları destekten dolayı Isparta Uygulamalı Bilimler Üniversitesi BAP Koordinasyon Birimi'ne teşekkürlerimizi sunariz. 


\section{KAYNAKLAR}

Başer, K. H. C. (2001). Her derde deva bir bitki Kekik. Bilim ve Teknik, Mayıs, 2001: 74-77.

Başer, K. H. C. (2002). Aromatic biodiversity among the flowering plant taxa of Turkey. Pure Appl. Chem., $74,527-545$.

Bayar, F. U., Çınar, O. (2020). Kültür koşullarında yetiştirilen farklı origanum spp. türlerinin bazı verim ve kalite parametreleri. Derim, 37(1), 10-17.

Baydar, H. (2001). Isparta'nın tıbbi ve aromatik bitkiler çeşitliliği ve kültüre alma olanakları. Süleyman Demirel Üniversitesi Fen Bilimleri Enstitüsü Dergisi, 5, 35-44.

Baydar, H. (2002). Isparta koşullarında İzmir kekiğinin (Origanum onites L.) verimi ve uçucu yağ kalitesi üzerine araştırmalar. Süleyman Demirel Üniversitesi Fen Bilimleri Enstitüsü Dergisi, 6, 15-21.

Cosentino, S., Tuberoso, C. I. G., Pisano, B., Satta, M., Mascia, V., Arzedi, E., Palmas, F. (1999). In vitro antimicrobial activity and chemical composition of Sardinian Thymus essential oils. Letters in Applied Microbiology, 29 (2), 130-135.

Çepel, N. (1996). Toprak ilmi. İÜ Yayın No 3945, Orman Fakültesi Yayın No: 438. İstanbul.

Epstein, E., Bloom, A. (2005). Mineral Nutrition of Plants: Principles and Perspectives. 2nd Edition, Sunderland, Mass: Sinauer Associates, USA.

Fageria, N. K., Baligar, V. C., Clark, R. B. (2002). Micronutrient in crop production. Adv. Agron., 77, 185-268.

Fageria, N. K. (2009). The Use of Nutrients in Crop Plants. CRC Pres, Boca Raton, Florida, New York.

Gardiner, D. T., Miller, R. W. (2008). Soils in Our Environment. 11th Edition, Pearson/Prentice Hall, Upper Saddle Hill, Ne Jersey, USA.

Gezgin, S., Hamurcu, M. (2006). Bitki beslemede besin elementleri arasındaki etkileşimin önemi ve bor ile diğer besin elementleri arasındaki etkileşimler. Selçuk Üniversitesi Ziraat Fakültesi Dergisi, 20(39), 24-31.

Hedhili, L., Romdhane, M., Abderrabba, A., Planche, H., Cherif, I. (2002). Variability in essential oil composition of Tunisian Thymus capitatus (L.) Hoffmanns. et Link. Fla vour and Fra grance Journ a 1, 17 (1), 17-26.

Jones, C., Jacobsen, J. (2001). Plant Nutrition and Soil Fertility. Nutrient management module 2. Montana State University Extension Service. Publication, 4449-2.

Kabouche, A., Kabouche, Z., Bruneau, C. (2005). Analysis of essential oil of Thymus numidicus (Poiret) from Algeria. Flavour and Fragrance Journal, 20, 235 236.

Kacar, B., Katkat, V. (2010). Bitki Besleme. 5. Bask1, Nobel Yayın Dağıtım Tic. Ltd. Şti, Kızılay-Ankara.
Kantarc1, M. D. (2000. Toprak İlmi. İÜ Toprak İlmi ve Ekoloji Anabilim Dalı, İ Ü Yayın No. 4261, Orman Fakültesi Yayın No. 462, İstanbul.

Karlı, B., Demir, Z., Dalgıç, A. (2020). Denizli İlinde Kekik Üretimi Yapan İssletmelerin Sosyo-Ekonomik Yapıs1 ve Sorunları. ISUBÜ Ziraat Fakültesi Dergisi, 15(2), 151-160.

Özgüven, M., Sekin, S., Gürbüz, B., Şekeroğlu, N., Ayanoğlu, F., Ekren, S. (2005). Tütün, Tıbbi ve Aromatik Bitkiler Üretimi ve Ticareti. TMMOB Ziraat Mühendisleri Odas1, Türkiye Ziraat Mühendisliği VI. Teknik Kongresi, 3-7 Ocak 2005, Bildiri Kitab1, 1:481-501, Ankara.

Rasooli, I., Mirmostafa, S. A. (2002). Antibacterial properties of Thymus pubescens and Thymus serpyllum essential oils. Fitoterapia,73(3), 244-250.

Rasooli, I., Rezaei, M. B., Allameh, A. (2006). Growth inhibition and morfological alterations of Aspergillus niger by essential oils from Thymus eriocalyx and Thymus x-porlock. Food Control, 17, 3-59.

Rice, R. W. (2007). The physiological role of minerals in the plant. In: Datnoff, L. E., Elmer, W. H., Huber, D. M. (ed.) Mineral nutrition and plant disease. The American Phytopathological Society, St. Paul, Minnesota, USA.

Saraçoğlu, M., Sürücü, A., Koşar, İ., Taş, M. A., Aydoğdu, M., Kara, H. (2014). Şanlıurfa ili Halfeti ilçesi topraklarının bazı özellikleri ve bitki besin elementi kapsamlarının belirlenmesi. Toprak Bilimi ve Bitki Besleme Dergisi, 2(2), 38-45.

Sargın, S. A., Selvi, S., Lopez, V. (2015). Ethnomedicinal plants of Sarigöl district (Manisa), Turkey. Journal of Ethnopharmacology, 171, 64-84.

Sarı, A. O., Oğuz, B. (2002. Kekik, Ege Tarımsal Araştırma Enstitüsü, Yayın No: 108, İzmir.

Selvi, S., Satıl, F., Polat, R., Çakılcığlu, U. (2012). Kazdağlarından (Balıkesir-Edremit) Toplanan ve Bölgedeki Aktarlarda Satılan Tıbbi Bitkiler Üzerine Bir Araştırma. Kazdağları III. Ulusal Sempozyumu, 24-26 Mayıs 2012, Edremit Balıkesir, s: 505-513.

Stahl-Biskup, E. (2002). Thyme as a herbal drugpharma copoeias and other product characteristics. In Stahl-Biskup and Saez (ed.) The genus Thymus, Taylor and Francis, London, 293.

Şafak, İ., Okan, T. (2004). Kekik, Defne ve Çamfıstığının Üretimi ve Pazarlaması. DOA Dergisi, 10, 101-129.

Tübives. (2021). Türkiye bitkileri veri servisi. http://www.tubives.com, Erişim: 04.03.2021

TÜİK, (2020a). Türkiye İstatistik Kurumu. https://biruni.tuik.gov.tr/medas/?kn=92\&locale=tr, Erişim tarihi: 13.07 .2020

TÜİK, (2020b). Türkiye İstatistik Kurumu. https://biruni.tuik.gov.tr/disticaretapp/distica ret.zul? param $1=25 \&$ param $2=0 \&$ sitcrev $=0 \&$ isicrev $=0 \&$ sa y a $\mathrm{c}=5802$, Erișim tarihi: 17.07.2020 
Wild, A. (1993). Soils and The Environment: An Introduction. 1st Edition, Cambridge University Pres, UK.

Yaşar, S., Sicim, N., (2021). Çeşitli gübre karışımı uygulamaları ve hasat zamanının kekik (Thymus sipyleus BOISS. subsp. sipyleus BOISS. var. sipyleus L.) bitkisinin ana uçucu bileşenleri üzerine etkileri. Türkiye Ormancılık Dergisi, 22(2), 151-156. 